\section{THE BUFFY COAT OF THE BLOOD DURIXG PREGNANCY.}

\author{
To the Editor of Tuf. Laxcet.
}

Sir:--In the seventh of M. Magendie's interesting lectures on the blood, now in course of publication in your valuable Journal, it is stated that Rasori (in a long article on phlogosis) asserts that the bufly coat is never wanting during the existence of pregnancy. Referring to the $39 t h$, and three following pages of the Leghorn edition of the work alluded to, entitled "Teoria della Flogosi," which was published shortly before the decease of this distinguished physician, it may be seen that he professed a very different opinion, which a few ex. tracts frum the work, bearing immediately on the subject, will, I think, very easily show. He says :- "Blood drawn during the period of gestation, when there are no symptoms to warrant bloodletting, generally exhibits no buffy coat, or at least such as is characteristic of inflammation. Sometimes there is secen a very thin covering resembling mucus, in colour scarcely to be distinguished from the serum, but such as no medical man of experience would nistake for the real buffy coat; moreover, the clot has not the firm consistence, nor is there that excess of serum which is observed in inflammatory diseases." He also states:- "That when bluod drawn during preguancy presents a distinct bufly coat, this appearauce should not be ascribed to pregnancy, but to a slow iuflammatory affection of the uterus or some other viscus, which this state has tended to increase." He mentions that he has frequently had occasion to ubserve that medical men have ascribed the bufted appearance of the hlood to the state of pregnancy, when lie has been able tu trace the cruse of it to some chronic inflammation, which this state had probably aggravated. He thus concludes the chapter on the subject in question:-_" I do not inean to deny the frequency of the buffy coat during pregnancy, but I maintain, in the first place, that it is not so common as is gene. rally supposed; in the second, that it is frequently caused by some obscure inflammatory affection; in the third, that preguancy, in a great number of cases, is accompauied by a more or less slight diathesis of stimulus, occasinued either by general plethora or by an increase of stimulus, which the uterus is, of necessity, at this period subjected to; in the fourth place, that these and other con. ditions of pregnancy tend to produce au increase of stimulus, and the consequent increase of the circulation und augmentation of heat, may cause the fibrine to acquire a firmer cousistence than it would possess in a state of health, which, as I have already explained, is the cause of the buffy coat bring produred."
M. Magendie also makes it appear that Rasori considered the $\mathrm{unff}_{\mathrm{f}}$ of the blood as " the inflammatory element par excellence." Another quotation, however, from the same work will show clearly that the author looked on the buff as the constant $\epsilon$ ffect and net the cause of inflammation. At the 38th page he draws the following deductions, which he gives as the fruit of forty years observation :-

"1. That the presence of the luff, as an effect, is a proof of the existence of the cause, namely, inflammation.

"2. That the more the buff increases in proportion to the two other component parts of the blood, the serum and clot, but more particularly with respect to the latter, the strouger nillst be considered the operation of the cause. Since, cateris paribus, the extent of the effect will be in proportion to the power of the cause, namely, inflainmation.

"3. As the same callse produces the ronsolidation of the fibriue, the reby allowing it to separate itself from the other two component parts, so the more the fibrine or buff becomes firm and cupped, the more power. ful must have been the cause, namely, a hicrher grade of inflammatory disease."

I am inclined to think that the majority of medical men in this country, who take the trouble to observe for thenselres, will coincide in opinion with Rasori rather than Magrendie and other's, who are of opinion that the buffy coat depenils on the size of the opening made in the vein, or on the shape or dimensions of the vessel which receives the blood. The author of the article "Conenue," in the "Dictionuaire alrege des Sciences Medicales,"has anulher opinion with regard to it equally at variance with that of Rasori; he sass:- "Hence it appears that the buffy coat of the blood is nothing more than the superior layer of the coagulum which has been modified, and, as it were, dried by the action of the air." I am, Sir, your very obedient servant,

79, Mosley-street, Mauchester, March 15, 18:34.

\section{IODIDE: OF POTASSIUM IN ACUTE RHELMATISM.}

\section{To the Editor of THE Laxcpt.}

Sir:-From ubsersiagr some cases of acute rheumatism sucressfully treated by the usp of the hydriodate of potash, or, more chemically speahing, the iorlide of potassium, as reported by C. D. Mackay, M.D., in your Junrnal of . Yarels 20d, 1839, I have been disposed to forward for publi. cation the folloning cases, which were treated in the Mnachester Ruyel Iufirmary, Auring the time $I$ acted as clinical clerk to 
the late Dr. Phillips, then lecturer on clini- $/$ which are extremely painful either to the cal medicine in that institution; and which cases perfectly accord with those of your excellent correspondent, Dr. Mackay; to these I add my humble testimony of the unequivocal action of the iodide of potas. sium in subduing that specific something,acute rheunatism. I am, Sir, yours most respectfully,

T. H. WARDLEWORTH.

Rochdale, March 21 st, 1839.

Casc 1.-Richard Rairford, mason, ztat. 30, a stout and healthy man, was attacked last Christmas with pain in his shoulder, coming on after exposure to cold and wet; he had always enjoyed good health previous to his present illness; and says he has led an intemperate life. He is now much reduced, and he has not been able to follow his employment since Christmas; the pain bas now extended to all his joints, which are swollen and exceedingly painful to the touch; he is restless during a great part of the nigbt; bowels regular; urine normal; tongue coated with a hrown fur; appetite good; pulse 80, and soft. He was ordered the following :-

Calomel and antimonial pouder, of each iij. grains; to be taken in the evening.

Senna draught, an ounce and a half, in the morning.

26. Has had his bowels freely moved from the draught; much the same in other respects. Ordered,

Antimonial mixture, xij. ounces;

I'ine of colchicum, half an ounce. Take one ounce thrice a day.

August 2. He is still suffering from severe pain in all his joints, which continue much swollen. Continue antimonial mixture, and omit the colchicum, on account of its action on the bowels. He was ordered to use the sulphur-bath every morning.

22. He has continued much the same, and, as he expresses himself, "better 'and worse," since last report. Omit sulphurbath, as he thought he was worse after using it.

Ioduret of starch, half a drachm, thrice a day.

29. No improvement. Habeat cald. bald. omni nocte.-(So in manuscript.)

Sept. 8 . He appeared to improve at first from the use of the ioduret, but he is now much worse, and unable to leave his bed Onit the ioduret.

Dorer's poutler, x. grains, twice a day.

9 . He is much better this morning, having passed a good night; and thiuks he shall improve under the use of the Dover's pow. der, from the relief he has already experienced in taking it.

16. Has steadily improved in his general health since last repurt; yet he suffers much from his feet and kuees being swollen, and

\section{Iodide of potash, half a drachm;}

Peppermint water, five ounces and a half; Syrup of crocus, half an ounce. One ounce thrice a day.

20. He now feels better than he has done for the last nine months; and he attributes his present improved condition solely to his last medieine. He now only complains of slight aching pains in his feet during the night.

28. Dismissed cured.

Case 2.-Mary Austin, æatat. 28, frametenter in a factory, was admitted October 2 , 1837. States that about six months ago she was travelling, per railway, from Manchester to Wigan; whilst on her journey she was much exposed to cold, accompanied with a heavy fall of snow. The day after she experienced severe pain in the larger joints; which was unattended with swelling, and which confined her to bed for nine weeks. She now complains of much pain in all her joints, which is considerably increased during the night; bowels costive; tongue clean; appetite good; urine normal; catamenia regular; pulse 60 .

Antimonial mixture, xij. ounces ;

Colchicum wine, half an ounce. Three ounces thrice a day.

6. Thinks herself improved, as far as regards the pain. She complains of the medicine making her sick, attended with pain in her stomach. Omit the mixture; take effervescing mixture, an ounce and a balf, every third hour.

9. Irritability of the stomach abated; much the same in other respects. Omit effervescing mixture.

Ioduret of starch, one scruple;

Antimonial powder, iij. grains. A powder every night.

25. Has continued to improve since last report.

31. She has complained, for the last day or two, of severe pain in her shoulders, which she considered to be occasioned by a change in the weather. Continue remedies.

Nov. 6. Has suffered for several days past from severe pain in her head, which is now relieved from the application of six leeches to each temple. Omit the ioduret, but continue the antimonial mixture.

9. Is much improved in her general health ; pain in her joints still remains undiminished. Iodide of potash, half a drachm;

Water, five ounces and a balf;

Sigrup of crocus, half an onnce. Take one ounce thrice a day.

27. Went ont this day cured, and she stated that the last medicine had relieved her more than all the others.

CAsE 3.-Anne Carty, ætat. 35, admitted Sept. 25, 1837. She is now suffering from 
severe pain in all the larger joints, which are much swollen, and, as she expresses it, "ready to burst ;" all which symptoms were occasioned by exposure to cold. Bowels rogular; tongue clean ; urine normal ; anorexia, \&c.; catamenia scanty, but regular; pulse 56, and soft.

Ioduret of starch, xij. grains, thrice a day. 29. No improvement. Increase the ioduret of starch to one scruple thrice a day.

Oct. 6. Is much improved from the use of the ioduret; less pain in all her joints; swelling much reduced; appetite good, čc.

19. She is now so far improved as to be enabled to leave her ward, and all she now complains of is a slight swelling and stiff. ness in her right ankle. Ordered to rub it every night with the following ointment:Iodine, one drachm;

Simple ointment, one ounce.

24. She has improved to the present time noder the use of the ointment, and the internal administration of the ioduret.

28. Dismissed cured.

\section{EFFECTS OF THE PRACTICE OF MEDICINE IN IGNORANT HANDS.}

\section{To the Editor of The Lancet.}

SIr:-The following case is one of many of a similar character, which have come under my observation, of ignorant and illegal practitioners, who take upon themselves the responsibility of bleeding and prescribing for disease with which they are totally unacquainted, causing the death, or protracted illness, of many of onr poor fellow-creatures. The present case is one of long standing disease of the aorta, and when first visited by this tooth-drawer and bleeder, the subject was in a state of great exhaustion and collapse. Without attempting to restore warmth by external application, or stimplants internally, he bled him (as he says) "without exercising any judgment whether it was proper or not, as it was not his businfss to do," merely because the wife requested him ; not satisfied with taking six or seven ounces, which he procured with the greatest difficulty, he wanted to lower the vital powers already too much depressed, still Jower, by abstracting a further quantity by " pricking him again.",

It is high time that some measures were taken to prevent a recurrence of these cases of gross malpractice, which are daily occurring. Having attended the inquest, and made, with Dr. Watts, the post-mortem examination, I send the particulars, if you think them sufficiently important, for insertion in The Lancer. I am, Sir, your obedient servant,

St. Peter's Church-side, Nottingham.
The first witness called was John .Marriolt, who deposed that he bad know a the deceas. ed, Thomas Glover, 40 years. Deceased was at work at Carrington, on Friday morn. ing, between nine and ten o'clock, and bad occasion to heat a piece of iron, which, when he had done, he laid on the vice I was filing at. I heard a groan, and turned round and saw him down on his knees; I called for assistance, and said Glover had fallen down in a fit; on raising him up we found him motionless, but placed him in a chair, and sponged his mouth and temples; he was breathing all the time, but I thought him dying; he remained ntarly half an hour in that senseless state, and then vomited a little something like gruel, after which he became more sensible and vomited again. He wished us to get him to the privy, and when there, said he must be down on bis face, or he should die; he lay on his belly a few minutes, and then we got him into a public-house. I then left him, and saw no more of him; he did not complain of pain in any particular part, but said he was exceedingly ill; have heard his son and daughter say he has had similar attacks before.

Elizabeth Clover, widow of the deceased, deposed :-Thomas Glover was 5.1 years old; has been in middling health, having been affected several tines in a similar man. ner, but was as well as usual on going to work at eight o'clock on Friday morning. I heard he had a fit at half-past nine or ten, and sent my son to fetch a doctor; he was brought home at half-past eleven, quite helpless, like a dead man. Mr. Spurr, who lives in Broad-street, who I believe is a cupper and bleeder, came to the house, my son having fetched him. I wished Mr.Spurr to bleed him, as he had been bled before when attacked in a similar way, and found relief. When he had bled him, he told me to fetch a surgeon, as he was not satisfied to leave him in the state he was in at that time. I think Mr. Spurr did not take so much as half a basinful of bluod. On going to the Uuion Hospital Dr. Watts came and ordered hot ale with ginger; be bad two pints at different times, after which he seemed better; complained of great pain all over, except his head; he was very cold, and 1 put hot bricks to his feet. After Ur. Watts was gone, he asked me to give him some laudanum; I gave him thirty drops in a cup of tea, after which he tossed about a good deal, and died in half an hour. It was my husband's wish that I should give him the landanum; I never perceived him at all insensible, and he breathed quite easy. When Mr. Spurr was bleeding him he knocked his arm about, and said, "it's of no use;" it was his agony that made him knock bis arm about. He did not bleed freely, and Mr. Spurr wanted to "prick bim again." W hen he was brought home his hands and feet, and all orer him, were as cold as death; and when he was 